\title{
Elusive case of dysphagia: Zenker's diverticulum masquerading as a cervical neoplasm
}

A 73-year-old man with previous skin cancer presented with a year long history of dysphagia and regurgitation. When evaluating the dysphagia 5 months earlier, esophagogastroduodenoscopy (EGD) was generally unremarkable, only revealing a possible short-segmented Barrett's esophagus, with no esophageal lesion noted. Magnetic resonance imaging (MRI) of the cervical spine (during follow-up from neck surgery) described a prevertebral soft tissue mass lesion measuring $2.2 \times 1.7 \mathrm{~cm}$. The patient was then referred to a tertiary cancer center for a suspected cervical neoplasm.

Computed tomography (CT) of the neck revealed a dilated proximal esophagus with a possible intramural esophageal mass ( $\triangleright$ Fig. 1 ). The patient was referred for endoscopic ultrasound (EUS) and possible EUS-guided fine-needle aspiration for tissue diagnosis and staging.

EGD revealed a Zenker's diverticulum with a large opening and impacted food in the upper esophagus below the upper esophageal sphincter, with a prominent cricopharyngeus muscle ( $>$ Fig. 2 ). There was no evidence of an esophageal mass ( Fig.3a); however, with the aid of water immersion, two distinct lumens were visualized in the upper esophagus ( $\mathbf{F i g . 3 b}$ ). The collapsed esophageal lumen next to the Zenker's diverticulum was possibly misdiagnosed as an intramural mass on the previous $C T$.

CT and MRI imaging are not considered relevant diagnostic methods [1] for Zenker's diverticulum, as there is a high possibility of interpreting the Zenker's diverticulum as a mass. In the current case, previous clinicians had mistakenly identified the collapsed esophageal lumen as an intramural esophageal mass. Therefore, we would like to emphasize the need for careful endoscopic evaluation of the esophagus all the way to the esophageal inlet for patients presenting with dysphagia, and for radiologists to consider this diagnosis while evaluating
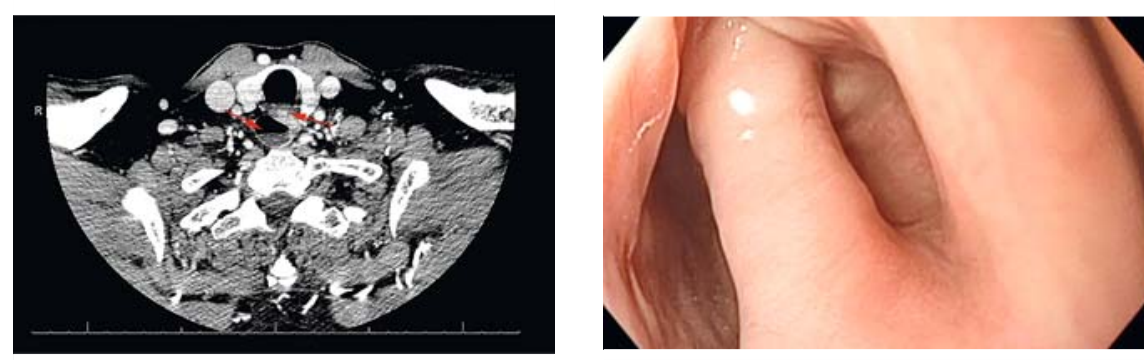

- Fig. 1 Computed tomography scan initially revealed a cervical esophageal dilation and an intramural mass in the left anterior esophageal wall (arrows).
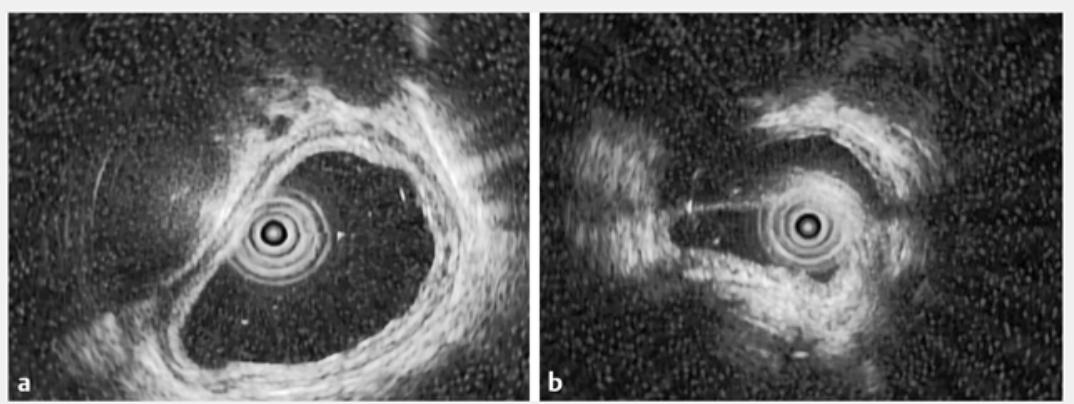

- Fig. 3 Endoscopic ultrasound imaging. a There was no evidence of an intramural mass in the surrounding esophageal wall. $\mathbf{b}$ Two distinct lumens were seen in the upper esophagus.

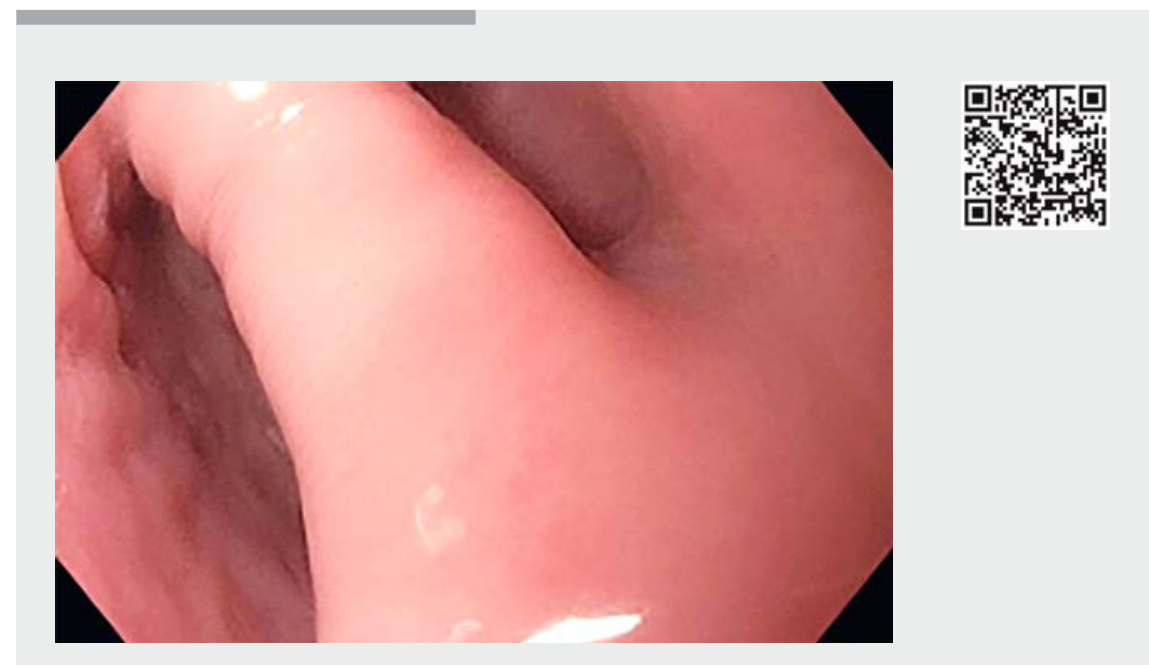

Video 1 Esophagogastroduodenoscopy and endoscopic ultrasound assessment of Zenker's diverticulum, which was initially interpreted as an intramural cervical mass on computed tomography. 
the $C T / M R I$ scans of the neck. Moreover, we would like to raise awareness of the potential to miss the diagnosis of Zenker's diverticulum during an EGD and the potential for misdiagnosing Zenker's diverticulum as an esophageal mass, as the appearance of a large Zenker's diverticulum on CT or MRI imaging is similar to a mass.

Endoscopy_UCTN_Code_CCL_1AB_2AC_3AF

Competing interests

None
The authors

Ben S. Singh, Irina M. Cazacu, Osman Ahmed, John R. Stroehlein, Manoop S. Bhutani

Department of Gastroenterology, Hepatology, and Nutrition, University of Texas MD Anderson

Cancer Center, Houston, Texas, United States

\section{Corresponding author}

\section{Manoop S. Bhutani, MD}

Department of Gastroenterology, Hepatology, and Nutrition Unit 1466, University of Texas MD Anderson Cancer Center, 1515 Holcombe Blvd., Houston, Texas 77030-4009, USA Fax: +1-713-563-4398

Manoop.Bhutani@mdanderson.org

Reference

[1] Achkar E. Esophageal diverticula. Gastroenterol Hepatol 2008; 4: 691-693

\section{Bibliography}

DOI https://doi.org/10.1055/a-0820-1965

Published online: 11.1.2019

Endoscopy 2019; 51: E63-E64

(c) Georg Thieme Verlag KG

Stuttgart · New York

ISSN 0013-726X

\section{ENDOSCOPY E-VIDEOS}

https://eref.thieme.de/e-videos

口回 Endoscopy E-Videos is a free access online section, reporting 促: on interesting cases and new

techniques in gastroenterological endoscopy. All papers include a high quality video and all contributions are freely accessible online.

This section has its own submission website at https://mc.manuscriptcentral.com/e-videos 